\title{
Pengaruh sistem pengendalian internal dan budaya organisasi terhadap kualitas pelayanan publik berkelanjutan
}

\author{
Nunik Lestari Dewi \\ Program Studi S-1 Akuntansi, Fakultas Ekonomi, Universitas Kristen Maranatha \\ Jalan Prof. drg. Suria Sumantri no. 65, Bandung \\ nunik1503@gmail.com \\ Yuliana Gunawan* \\ Program Studi S-1 Akuntansi, Fakultas Ekonomi, Universitas Kristen Maranatha \\ Jalan Prof. drg. Suria Sumantri no. 65, Bandung \\ yuliana_ok99@yahoo.com \\ Soddin Mangunsong \\ Program Studi S-1 Akuntansi, Fakultas Ekonomi, Universitas Kristen Maranatha \\ Jalan Prof. drg. Suria Sumantri no. 65, Bandung \\ soddinmangunsong@yahoo.com \\ Yohana Meiliana \\ Program Studi S-1 Akuntansi, Fakultas Ekonomi, Universitas Kristen Maranatha \\ Jalan Prof. drg. Suria Sumantri no. 65, Bandung \\ yohanamei13@gmail.com \\ *Penulis Korespondensi
}

Submitted: Nov 09, 2020; Reviewed: Nov 16, 2020; Accepted; May 04, 2021

\begin{abstract}
Founder and central leaders of policymakers and development in the health sector said several obstacles must be addressed in the health service system, one of which is the low level of hospital services in Indonesia. The health service system in Indonesia still needs to be improved by the government, both in terms of equity, regulation, and system integration. To achieve the goals of sustainable health services, it is necessary to implement an integrated system (internal control system) in the hospital. An effective internal control system can anticipate various environmental changes that occur quickly, increase operational effectiveness and efficiency, and anticipate law violations. To improve the quality of sustainable health services, apart from implementing an internal control system, hospitals also need to carry out various innovations to provide changes in the bureaucratic climate. Innovations are carried out based on learning on all processes that have been carried out by the hospital. Therefore, the objective to be achieved in this study is to determine the effect of internal control systems and organizational culture (innovation and learning culture) on the quality of sustainable public services at BLUD RSUD dr. Slamet, Garut Regency. The data was collected using a survey method using a questionnaire. Data were analyzed using multiple regression methods. The results showed no influence on the internal control system on the quality of sustainable public services, but there was an influence of organizational culture on the quality of sustainable public services.
\end{abstract}

Keywords: internal control system; organizational culture; quality of sustainable public services 
Abstrak: Pendiri dan pemimpin pusat dari pembuat kebijakan dan pengembangan di bidang kesehatan mengatakan terdapat beberapa kendala yang harus dibenahi dalam sistem pelayanan kesehatan, salah satunya adalah rendahnya tingkat pelayanan rumah sakit di Indonesia. Sistem pelayanan kesehatan di Indonesia masih perlu dilakukan pembenahan oleh pemerintah, baik dalam hal pemerataan, regulasi, maupun integrasi sistem. Agar tujuan pelayanan kesehatan tercapai secara berkelanjutan, maka perlu diterapkan sistem yang terintegrasi (sistem pengendalian internal) di rumah sakit. Sistem pengendalian internal yang efektif mampu mengantisipasi berbagai perubahan lingkungan yang terjadi secara cepat, meningkatkan efektivitas dan efesiensi operasional, serta mengantisipasi terjadinya pelanggaran hukum. Untuk meningkatkan kualitas pelayanan kesehatan yang berkelanjutan, selain penerapan sistem pengendalian internal, rumah sakit juga perlu melakukan berbagai inovasi agar dapat memberikan perubahan iklim birokrasi. Inovasi dilakukan berdasarkan pembelajaran atas segala proses yang telah dijalankan oleh rumah sakit. Oleh karena itu, tujuan yang hendak dicapai dalam penelitian ini adalah untuk mengetahui pengaruh sistem pengendalian internal dan budaya organisasi (budaya inovasi dan pembelajaran) terhadap kualitas pelayanan publik berkelanjutan di BLUD RSUD dr. Slamet Kabupaten Garut. Teknik pengambilan data dilakukan dengan metode survei menggunakan alat bantu kuesioner. Data dianalisis menggunakan metode regresi berganda. Hasil penelitian menunjukkan tidak terdapat pengaruh sistem pengendalian internal terhadap kualitas pelayanan publik berkelanjutan, namun terdapat pengaruh budaya organisasi terhadap kualitas pelayanan publik yang berkelanjutan.

Kata kunci: budaya organisasi; kualitas pelayanan publik berkelanjutan; sistem pengendalian internal

\section{PENDAHULUAN}

Menurut survei yang dilakukan oleh Lembaga Ombudsman Republik Indonesia, dapat disimpulkan bahwa kualitas layanan publik di Indonesia tahun 2018 masih tergolong rendah (Ombudsman Republik Indonesia, 2019) Sementara itu, tugas utama pemerintah sebagai penyelenggara negara yaitu memberikan pelayanan publik kepada masyarakat (Hardiyansyah, 2018). Memberikan pelayanan publik merupakan hal dasar dalam penyelenggaran suatu organisasi publik, sekaligus menjadi indikator utama dalam pengukuran kinerja organisasi publik, oleh karena itu organisasi publik harus diatur dengan manajemen publik yang berpusat pada kinerja pelayanan publik dan kualitas pelayanan (Hayat, 2017). Organisasi publik di Indonesia, di antaranya adalah pemerintah pusat, pemerintah daerah, partai politik, LSM, yayasan, lembaga keagamaan, lembaga pendidikan, dan lembaga kesehatan (Puskesmas, Rumah Sakit). Badan Layanan Umum Daerah (BLUD) merupakan bagian dari Satuan Kerja Perangkat Daerah (SKPD), yang berstatus hukum tidak terpisah dari Pemda, yang memiliki fleksibilitas berupa keleluasaan dalam menerapkan praktik-praktik bisnis yang sehat untuk meningkatkan pelayanan kepada masyarakat. SKPD yang berstatus BLUD adalah Rumah Sakit Umum Daerah (RSUD).

Sistem pelayanan kesehatan di Indonesia masih perlu dilakukan pembenahan, baik dalam hal pemerataan, regulasi maupun integrasi sistem (Ulya, 2019). Terdapat enam kendala yang harus dibenahi dalam sistem pelayanan kesehatan, di antaranya: tidak berkembangnya sistem kesehatan digital yang menyebabkan daerah-daerah terpencil tidak dapat mengakses kesehatan dari jauh, rendahnya regulasi untuk pengguna layanan kesehatan digital, jumlah penduduk yang banyak akan tetapi sistem kesehatan tidak mumpuni, distribusi kesehatan yang masih terkendala akibat tidak dapat ditempuh dengan jalur darat karena Indonesia merupakan negara kepulauan, pelayanan rumah sakit di Indonesia relatif rendah, dan tidak dapat memanfaatkan kemajuan teknologi dengan baik untuk pelayanan kesehatan (Ulya, 2019).

Dalam upaya meningkatkan pelayanan kesehatan di Kabupaten Garut, Dinas Kesehatan Kabupaten Garut menyediakan pusat layanan kedaruratan untuk menyediakan pelayanan kepada masyarakat yang membutuhkan bantuan pelayanan kesehatan darurat selama 24 jam berupa Public Safety Center (Zaenal, 2018). Layanan ini merupakan layanan inovasi dari Dinas Kesehatan Kabupaten Garut yang dapat menerima informasi darurat dari masyarakat yang ada di seluruh wilayah Kabupaten Garut. Melalui Public Safety Center (PSC), pelayanan publik khususnya bidang kesehatan 100 
di Kabupaten Garut menjadi meningkat dan berkembang. RSUD dr. Slamet juga terkoordinasi dengan PSC Dinkes Garut, yang mana rumah sakit siap melayani pasien rujukan yang diantarkan PSC selama 24 jam.

Berdasarkan penelitian Ilias et al. (2016), otoritas lokal Malaysia yang memiliki kepedulian tinggi terhadap pengendalian internal menghasilkan kualitas layanan kinerja yang lebih baik dibandingkan otoritas lokal Malaysia yang tidak memiliki kepedulian terhadap pengendalian internal. Penelitian Dhillon \& Andri (2018) menunjukkan bahwa dari kelima elemen pengendalian internal COSO, hanya dua elemen yaitu aktivitas pengendalian dan penilaian risiko yang berpengaruh terhadap kinerja karyawan di Rumah Sakit Umum di Tangerang Selatan. Selanjutnya, penelitian Atmojo et al. (2018) menunjukkan bahwa budaya organisasi memiliki pengaruh yang positif dan signifikan terhadap kinerja pegawai Rumah Sakit QIM Batang.

Mengacu pada fenomena dan penelitian sebelumnya, maka peneliti ingin melakukan penelitian yang berkaitan dengan sistem pengendalian internal, budaya organisasi (mencakup budaya inovasi dan budaya pembelajaran), dan kualitas pelayanan rumah sakit. Perbedaan dengan penelitian sebelumnya terdapat pada tempat pengambilan data, yaitu di BLUD RSUD dr. Slamet Garut. Alasan pengambilan data dilakukan di RSUD dr. Slamet Garut dengan dasar tahun 2018, yaitu bahwa RSUD dr. Slamet Kabupaten Garut meraih penghargaan tertinggi berupa predikat bintang lima dalam Rapat Paripurna (Suherlan, 2018). Hal tersebut menyatan bahwa kualitas pelayanan kesehatan yang diberikan oleh rumah sakit telah sesuai dengan ketentuan pelayanan kesehatan menurut badan akreditasi. Setiap tahun, RSUD dr. Slamet Kabupaten Garut selalu melakukan survei ulang atas standar pelayanan guna memertahankan akreditasi dan rumah sakit terkoordinasi dengan Public Safety Center Dinkes Garut, yang mana rumah sakit selalu siap melayani pasien rujukan yang diantarkan Public Safety Center selama 24 jam. Oleh sebab itu, penelitian ini dilakukan dengan harapan untuk mengetahui pengaruh sistem pengendalian internal dan budaya organisasi terhadap kualitas pelayanan publik berkelanjutan di BLUD RSUD dr. Slamet Kabupaten Garut.

Diperlukan penerapan standar minimal dalam manajemen berbasis kinerja untuk memberikan jaminan terhadap kualitas pelayanan publik yang berkelanjutan, karena kualitas pelayanan publik menjadi indikator kesuksesan pelayanan publik yang diberikan. Membangun pelayanan publik yang berkualitas secara berkelanjutan dapat difokuskan pada delapan prinsip excellent (IAI, 2017). Prinsip pertama orientasi hasil (berhubungan dengan segala upaya BLUD untuk mencapai target yang telah ditetapkan), prinsip kedua fokus pada pelanggan atau masyarakat (BLUD harus fokus pada kebutuhan masyarakat atau pelanggan saat ini dan masa depan, mengikutsertakan masyarakat atau pelanggan dalam pengembangan produk dan layanan serta peningkatan kinerjanya), prinsip ketiga kepemimpinan dan tujuan yang konsisten (BLUD memerlukan pemimpin yang mampu membangun pernyataan misi dan visi serta nilai-nilai organisasi yang jelas serta membangun dan menjaga lingkungan internal yang dapat mendorong seluruh pegawai untuk sepenuhnya terlibat dalam upaya pencapaian tujuan organisasi), serta prinsip keempat pengelolaan berdasarkan proses dan fakta (sumber daya dan aktivitas harus dikelola sebagai proses dan keputusan yang efektif berdasarkan hasil analisa data dan informasi).

Selanjutnya, prinsip kelima pengembangan dan keterlibatan pegawai (menciptakan lingkungan kerja yang dapat mendukung berkembangnya share values dan suatu budaya saling percaya, keterbukaan, pemberdayaan, dan pengakuan), prinsip keenam pembelajaran, inovasi, dan peningkatan berkelanjutan (diperlukan pembelajaran berkelanjutan untuk menciptakan inovasi dan peningkatan peluang), prinsip ketujuh pengembangan kemitraan (BLUD harus membangun dan menjaga kemitraan yang memiliki nilai tambah untuk mencapai targetnya), serta prinsip kedelapan tanggung jawab sosial (BLUD harus mendefinisikan tanggung jawab sosialnya masing-masing, menghargai keberlangsungan ekologi, dan berupaya untuk memenuhi ekspektasi utama dan berbagai persyaratan baik dari komunitas lokal maupun global). Kualitas pelayanan publik yang optimal didukung oleh banyak faktor, yaitu adanya jiwa kepemimpinan, memiliki budaya organisasi, memiliki kelembagaan, memiliki tata kerja, terdapat ketentuan pelayanan, pengaturan pengaduan masyarakat, pengendalian dan evaluasi, sarana dan prasarana, pemakaian teknologi informasi, serta pengelolaan SDM (Hayat, 2017).

Budaya organisasi mencerminkan ciri atau karakteristik suatu organisasi, oleh sebab itu budaya organisasi harus selalu diubah dan diperbaiki secara berkesinambungan sejalan dengan kecenderungan global yang semakin cepat berubah (Wibowo, 2016). Diperlukan budaya inovasi dalam 
organisasi, yang dapat mendorong para anggotanya untuk membuat atau mengembangkan ide kreatif dan inovatif demi kemajuan dan perkembangan dari organisasi tersebut.

Menurut Suwarno (2008), inovasi di sektor publik merupakan salah satu jalan untuk mengatasi kebuntuan organisasi di sektor publik. Inovasi dalam layanan publik dapat berupa pembaharuan pelayanan yang lebih kreatif atau menciptakan pelayanan publik yang baru (Setijaningrum, 2009). Dalam pelaksanaannya, sektor publik berinovasi untuk menjaga kepentingan publik. Langkah-langkah yang ditempuh untuk mengembangkan budaya inovasi dalam BLUD adalah gagasan inovasi, desain inovasi, implementasi inovasi, dan evaluasi inovasi (IAI, 2017).

Menurut Wibowo (2016), budaya organisasi dapat bertumbuh melalui proses perubahan secara berhahap dalam waktu yang lama dari gagasan yang dihasilkan dan dapat berkembang dengan cara proses pembelajaran dan pengalaman. Menurut Schein (2010), terdapat tujuh unsur dari budaya pembelajaran, yaitu: atensi terhadap orang, keyakinan bahwa keinginan untuk belajar dan menilai pembelajaran dan perubahan sebagai hal yang penting, adanya optimistis bahwa dunia dapat berubah, organisasi memerlukan untuk pembelajaran, memiliki komitmen bersama, perlu dikembangkan belajar berpikir secara sistematis, serta koordinasi dan koperasi yang saling tergantung semakin penting. Budaya pembelajaran meliputi empat hal, di antaranya (IAI, 2017): (1) mengidentifikasi efektivitas manajemen kualitas untuk meningkatkan pelaksanaan manajemen kualitas; (2) membuat langkah tindak lanjut awal berupa melakukan kajian-kajian dalam rangka meningkatkan kualitas tata kelola; (3) sharing system untuk mensosialisasikan hasil kajian pengembangan manajemen kualitas yang telah dilaksanakan; dan (4) mendokumentasikan hasil kajian pengembangan ke dalam database yang terpusat. Saat ini, zaman semakin canggih dan berkembang cepat. Hal tersebut mendorong organisasi sektor publik untuk mengikuti perkembangan yang terjadi agar mampu bersaing dan tidak tertinggal; budaya inovasi dan pembelajaran digunakan untuk mengembangkan quality management secara berkelanjutan.

Selain budaya inovasi dan pembelajaran untuk mencapai tujuan pelayanan, diperlukan sistem pengendalian internal yang terintegrasi satu sama lain. Pada saat suatu organisasi memiliki pengendalian internal yang efektif, maka organisasi dapat mengantisipasi berbagai perubahan lingkungan yang terjadi. Pengendalian internal yang digunakan untuk peningkatan kualitas pelayanan publik termuat dalam PP No. 60 tahun 2008 tentang Sistem Pengendalian Intern Pemerintah (BPK, 2008) yang terdiri atas lima unsur, yaitu: (1) lingkungan pengendalian yang berkaitan dengan perilaku, kepedulian, dan tindakan-tindakan dari pejabat pengelola, dewan pengawas, dan staf dalam mengembangkan dan menerapkan pengendalian intern dan tata kelola yang baik; (2) identifikasi risiko dan analisis resiko dilakukan untuk menjaga, menerapkan, atau meninjau pengendalian internal di lingkungan BLUD; (3) aktivitas pengendalian dikembangkan dan diterapkan pada seluruh proses operasional dan keuangan, termasuk di dalamnya kegiatan review kinerja, pengendalian fisik atas aset, serta pengendalian umum dan aplikasi pada sistem teknologi; (4) diperlukan informasi yang dapat diakses dan adanya saluran komunikasi dua arah yang berjalan secara efektif; dan (5) diperlukan kegiatan penilaian secara berkesinambungan terhadap efetivitas atas rancangan dan kegiatan sistem pengendaian internal dengan memberikan masukan berupa tindakan perbaikan yang ditujukan untuk membantu dewan pengawas, pejabat pengelola, dan manajemen tingkat menengah untuk memastikan adanya pemasangan dan penerapan pengendalian yang tepat. Kelima unsur pengendalian internal memiliki hubungan yang erat satu dengan yang lainnya.

Penelitian Atmojo et al. (2018) juga menunjukkan pentingnya budaya organisasi untuk menunjang dan merangsang kinerja sumber daya manusia. Hasil penelitian menunjukkan bahwa budaya organisasi memiliki pengaruh yang positif dan signifikan terhadap kinerja pegawai Rumah Sakit QIM Batang. Dalam penelitian tersebut, dijelaskan bahwa budaya organisasi berperan penting dalam merangsang semangat kerja SDM. Kemudian penelitian Dhillon \& Andri (2018), menemukan pentingnya penerapan kebijakan dan peraturan perundang-undangan dalam meningkatkan kinerja pegawai serta menentukan reward dan punishment sebagai alat pengendali karyawan untuk mengarahkan kinerja karyawan. Hasil penelitian menunjukkan bahwa dari kelima elemen pengendalian internal COSO, hanya dua elemen yaitu aktivitas pengendalian dan penilaian risiko yang berpengaruh terhadap kinerja karyawan pada Rumah Sakit Umum di Tangerang Selatan. Berdasarkan teori dan penelitian sebelumnya, maka hipotesis yang diajukan dalam penelitian ini adalah sebagai berikut. 
$\mathrm{H}_{1}$ : Terdapat pengaruh sistem pengendalian internal terhadap kualitas pelayanan publik yang berkelanjutan.

$\mathrm{H}_{2}$ : Terdapat pengaruh budaya organisasi terhadap kualitas pelayanan publik yang berkelanjutan.

\section{METODE}

Populasi dalam penelitian ini adalah seluruh karyawan di BLUD RSUD dr. Slamet Kabupaten Garut sebanyak 1.191 orang, yang terdiri atas 53 orang medis, 593 orang perawat, 55 orang bidan, 41 orang farmasi, 4 orang kesehatan lingkungan, 6 orang gizi, 3 orang terapis, 21 orang teknisi medis, 33 orang teknik biomedika, 28 orang struktural, serta 354 orang manajemen. Sampel ditentukan berdasarkan teknik purposive sampling, dengan kriteria: responden harus memahami betul tentang pengendalian internal, responden harus di level yang memahami tentang budaya organisasi yang ada, serta responden berada di level pengambil kebijakan untuk pelayanan publik dan eksekutor pemberian layanan publik. Oleh sebab itu, sampel yang diambil dalam penelitian ini adalah semua pimpinan yang ada di BLUD RSUD dr. Slamet Kabupaten Garut (seperti: direktur, wakil direktur, kepala bagian dan sub bagian, kepala bidang dan seksi, penanggung jawab, serta koordinator bagian) sebanyak 125 orang. Responden 125 orang adalah semua pimpinan di seluruh bagian dalam organisasi. Metode pemungutan data yang digunakan dalam penelitian ini adalah metode survei, dengan alat bantu angket. Teknik survey digunakan sebagai langkah pencarian data primer. Penyebaran kuesioner dilakukan melalui Kepala Bagian Sumber Daya Manusia RSUD dr. Slamet Garut, yaitu Bapak H. Iwa Kartiwa, S.K.M., MH. Kes. Peneliti mendapat bantuan untuk mendistribusikan kuesioner tersebut. Uji instrumen dilakukan dengan menguji validitas dan reliabilitas. Ketentuan validitas dikatakan sahih apabila $\mathrm{r}$ hitung lebih besar dari $\mathrm{r}$ kritis 0,30 (Sugiyono \& Susanto, 2015). Batasan skor reliabilitas Cronbach's Alpha menurut Hartono (2008), yaitu memiliki reliabilitas tinggi apabila nilainya di atas 0,7 . Peneliti juga melakukan uji normalitas untuk memastikan data yang dipakai berdistribusi normal dengan syarat hasil Kolmogorov Smirnov lebih besar dari 0,05 (Sugiyono \& Susanto, 2015). Dalam menguji hipotesis, peneliti memakai metode analisis regresi berganda, dengan persamaan sebagai berikut.

Keterangan:

$$
\mathrm{Y}=\mathrm{a}+\mathrm{b} 1 \mathrm{X}_{1}+\mathrm{b} 2 \mathrm{X}_{2}+\mathrm{e}
$$

$$
\begin{aligned}
& \text { Y: Kualitas Pelayanan Publik Berkelanjutan } \\
& \text { a: Konstanta } \\
& \mathrm{X}_{1} \text { : Sistem Pengendalian Internal } \\
& \mathrm{X}_{2} \text { : Budaya Organisasi (Budaya Inovasi dan Pembelajaran) } \\
& \text { e: Error }
\end{aligned}
$$

Kriteria pengambilan keputusan yaitu nilai sig. $<0,05$ maka $_{\mathrm{a}}$ diterima (Sugiyono \& Susanto, 2015).

\section{HASIL DAN PEMBAHASAN}

\subsection{Hasil Penelitian}

Instrumen atau kuesioner yang didistribusikan sebanyak 125 kuesioner dan hanya 83 kuesioner yang kembali dan seluruhnya dapat diolah. Data dari 83 responden tersebut diinput, kemudian diolah dengan alat bantu SPSS. Data hasil penelitian atas pengujian validitas dilakukan melalui korelasi Pearson. Variabel $\mathrm{X}_{1}$ (sistem pengendalian internal) terdiri dari tiga belas indikator berdasarkan lima unsur sistem pengendalian internal pemerintah (SPIP) dalam PP No. 60 tahun 2008, variabel $\mathrm{X}_{2}$ budaya organisasi (budaya inovasi dan budaya pembelajaran) dengan sembilan belas indikator berdasarkan budaya inovasi dan pembelajaran yang digagaskan oleh IAI Kompartemen Akuntan Sektor Publik tahun 2017, dan variabel Y (kualitas pelayanan publik berkelanjutan) terdiri dari sembilan indikator berdasarkan prinsip excellent pelayanan publik yang berkualitas yang digagaskan IAI Kompartemen Akuntan Sektor Publik tahun 2017. 
Hasil uji validitas dinyatakan valid, karena nilai korelasi yang dihasilkan memenuhi standar validitas di atas 0,3 . Hal tersebut menunjukkan bahwa pernyataan-pernyataan yang diajukan dalam kuesioner mampu mengukur variabel yang akan diukur. Hasil pengujian reliabilitas digunakan untuk mengukur konsistensi butir pernyataan dalam kuesioner dengan menggunakan analisis cronbach alpha. Pengujian reliabilitas untuk semua pertanyaan yang diajukan di setiap variabelnya, hasilnya di atas 0,7 , sehingga dinyatakan reliabel.

Uji normalitas data dilakukan dengan menggunakan uji statistik non-parametrik KolmogorovSmirnov (K-S), nilai asymp. sig. (2-tailed) sebesar 0,825 dengan kata lain nilai asymp. sig (2-tailed) lebih besar dari lima persen $(0,05)$, maka dapat disimpulkan bahwa data residual berdistribusi normal. Hasil uji regresi berganda dalam penelitian ini dapat dilihat pada Tabel 1.

Tabel 1. Ringkasan hasil analisis regresi

\begin{tabular}{lccc}
\hline Variabel & Koefisien Regresi & thitung & Sig. \\
\hline Konstanta & 10,082 & & \\
Sistem Pengendalian Internal (X1) & 0,145 & 1,690 & 0,095 \\
Budaya Organisasi (X2) & 0,254 & 4,145 & 0,000 \\
\hline Fhitung $=22,011$ & & & \\
Sig. $=0,000$ & & & \\
RSquare $=0,355$ & & &
\end{tabular}

Tabel 1 menunjukkan bahwa tidak terdapat pengaruh sistem pengendalian internal terhadap kualitas pelayanan publik berkelanjutan di BLUD RSUD dr. Slamet Kabupaten Garut (nilai sig. 0,095 lebih besar dari 0,05), artinya hipotesis pertama tidak didukung dan terdapat pengaruh budaya organisasi terhadap kualitas pelayanan publik berkelanjutan di BLUD RSUD dr. Slamet Kabupaten Garut (nilai sig. 0,000 lebih kecil dari 0,05), artinya hipotesis kedua didukung. Pengujian secara simultan menunjukkan nilai sig. sebesar 0,000 lebih kecil dari 0,05, yang artinya terdapat pengaruh sistem pengendalian internal dan budaya organisasi terhadap kualitas pelayanan publik berkelanjutan di BLUD RSUD dr. Slamet Kabupaten Garut. Besaran pengaruh dapat dilihat dari nilai Rsquare, yaitu sebesar 0,355 atau 35,5 persen, artinya sistem pengendalian internal dan budaya organisasi berpengaruh terhadap kualitas pelayanan yang berkelanjutan sebesar 35,5 persen. Persamaan regresi yang diperoleh adalah $\mathrm{Y}=10,082+0,145 \mathrm{X}_{1}+0,254 \mathrm{X}_{2}+\mathrm{e}$, yang artinya jika nilai sistem pengendalian internal dan budaya organisasi meningkat, maka nilai kualitas pelayanan publik berkelanjutan di BLUD RSUD dr. Slamet Kabupaten Garut ikut meningkat.

\subsection{Pembahasan}

Hasil uji parsial menunjukkan tidak terdapat pengaruh yang signifikan dari sistem pengendalian internal (SPI) terhadap kualitas pelayanan publik yang berkelanjutan, artinya sistem pengendalian internal yang ada di rumah sakit dr Slamet masih belum dapat mendukung secara optimal pencapaian kualitas pelayanan publik yang berkelanjutan. Jika dilihat dari hasil tabulasi data, hal tersebut dapat terjadi akibat kurangnya sosialisasi pentingnya SPI, pedoman pemisahan tugas yang masih dianggap belum memadai, dan saluran komunikasi dua arah yang masih kurang efektif. Hal ini sejalan dengan penelitian Ilias et al. (2016) yang menunjukkan bahwa pada saat ada kepedulian tinggi terhadap pengendalian internal akan menghasilkan kualitas layanan kinerja yang lebih baik dibandingkan jika tidak ada kepedulian terhadap pengendalian internal. Sejalan dengan penelitian Dhillon \& Andri (2018) yang menunjukkan bahwa dari kelima elemen pengendalian internal COSO, terdapat tiga elemen pengendalian internal yang tidak berpengaruh terhadap kinerja karyawan pada Rumah Sakit Umum di Tangerang Selatan.

Berbeda dengan hasil pengujian hipotesis pertama, hasil penelitian menunjukkan bahwa terdapat pengaruh yang signifikan dari budaya organisasi terhadap kualitas pelayanan publik yang berkelanjutan. Hal tersebut sejalan dengan penelitian Atmojo et al. (2018) bahwa budaya organisasi memiliki pengaruh yang positif dan signifikan terhadap kinerja pegawai Rumah Sakit QIM Batang serta sejalan dengan penelitian Hilda (2014) bahwa strategi inovasi layanan dapat meningkatkan 104 
kualitas pelayanan di Kantor Pertanahan Kota Surabaya II menjadi lebih cepat dan efisien. Kinerja pegawai di rumah sakit menunjukkan kualitas pelayanan yang diberikan karyawan kepada publik.

Pelayanan di RS adalah salah satu bentuk pelayanan publik, karena RS merupakan salah satu jenis organisasi sektor publik. Kematangan Badan Layanan Umum Daerah Rumah Sakit Daerah dalam mengelola sistem pengendalian internal dapat memberikan jaminan yang memadai bahwa tujuan organisasi, yaitu memberikan kualitas pelayanan kesehatan yang baik dapat tercapai. Pengembangan budaya kerja yang berfokus pada budaya inovasi dan pembelajaran di organisasi BLUD dapat meningkatkan kualitas pelayanan publik yang mengedepankan efisiensi, produktivitas, serta praktik bisnis yang sehat (IAI, 2017). Faktor budaya organisasi dapat mendukung pengoptimalan pelayanan publik (Hayat, 2017).

Setiap pelayanan jasa yang diberikan oleh rumah sakit harus memberikan jaminan kualitas pelayanan yang berkelanjutan. Tentunya, agar kualitas pelayanan yang diberikan baik serta terus menerus membaik atau sesuai standar dan terus menerus melebihi standar (Standar Nasional Akreditasi Rumah Sakit), perlu ditopang oleh sistem pengendalian internal yang efektif dan efisien serta perlu didukung oleh budaya organisasi yang penuh dengan inovasi dan pembelajaran.

\section{SIMPULAN DAN SARAN}

Simpulan dari penelitian ini bahwa tidak terdapat pengaruh sistem pengendalian internal terhadap kualitas pelayanan publik berkelanjutan di BLUD RSUD dr. Slamet Kabupaten Garut, hal tersebut menunjukkan masih kurang optimalnya SPI yang ada di RS dalam mendukung kualitas pelayanan publik yang berkelanjutan. Mengingat pentingnya sistem pengendalian internal untuk menunjang pelayanan publik yang berkelanjutan, oleh karena itu perlu dipastikan bahwa sistem pengendalian internal di BLUD RSUD dr. Slamet Kabupaten Garut sudah diterapkan secara efektif dan efisien. Simpulan lainnya menunjukkan bahwa terdapat pengaruh budaya organisasi terhadap kualitas pelayanan publik yang berkelanjutan di BLUD RSUD dr Slamet Garut. Budaya organisasi (budaya inovasi serta budaya pembelajaran) harus dikembangkan sesuai perkembangan kebutuhan pelayanan publik.

Penelitian ini memberikan saran bagi seluruh pimpinan yang ada di RSUD dr. Slamet Kabupaten Garut agar terus memelihara implementasi sistem pengendalian internal untuk menjaga dan memelihara efektivitas dan efisiensi operasional rumah sakit yang tentunya akan berdampak pada peningkatan kualitas pelayanan RSUD dr. Slamet Garut, seperti menciptakan lingkungan pengendalian yang baik dimulai dari keteladanan para pemimpin dalam bertindak yang tentunya akan ditiru bawahan, mensosialisasikan pentingnya SPI, membuat pedoman pemisahan tugas secara memadai, menciptakan saluran komunikasi dua arah yang efektif, melakukan identifikasi dan analisis risiko terhadap pelaksanaan sistem pengendalian internal, serta melakukan evaluasi secara periodik mengenai implementasi sistem pengendalian internal di rumah sakit.

Selain itu, perlu ada penciptaan budaya inovasi yang mampu menjawab perubahan lingkungan yang cepat dan budaya pembelajaran di lingkungan rumah sakit agar bisa menjawab kebutuhan pelayanan masyarakat, khususnya di bidang kesehatan. Manajemen harus terbuka terhadap setiap gagasan yang muncul baik dari para pegawai, pasien, dan masyarakat, agar manajemen mampu menemukan gagasan mana yang paling inovatif dan mampu diimplementasikan di rumah sakit serta memberikan pelayanan terbaik bagi publik. Gagasan dapat diberikan melalui kotak saran yang disediakan rumah sakit di pojok-pojok pelayanan rumah sakit, email rumah sakit yang dicantumkan di laman rumah sakit, serta membuat media sosial yang dapat diakses oleh masyarakat luas sehingga bisa berkomunikasi langsung melalui media sosial (seperti Instagram, Facebook, dan lainnya).

Bagi yang berminat untuk melakukan penelitian selanjutnya, diharapkan dapat mengembangkan pengujian ini dengan menambahkan variabel-variabel lain, seperti kepemimpinan, kelembagaan, standar pelayanan, pengelolaan pengaduan masyarakat, sarana dan prasarana, penggunaan teknologi informasi, serta pengelolaan sumber daya manusia yang diduga dapat memengaruhi kualitas pelayanan publik berkelanjutan. 


\section{ACKNOWLEDGEMENTS}

1. Ucapan terima kasih kepada Bapak Direktur RSUD dr. Slamet Kabupaten Garut beserta jajarannya, karena telah menerima dan memberikan ijin bagi tim penelti untuk melakukan penelitian di RSUD dr. Slamet Kabupaten Garut, khususnya pada Bapak H. Iwa Kartiwa, SKM., MH. Kes selaku Kepala Sumber Daya Manusia yang sangat membantu peneliti dalam mendistribusikan kuesioner penelitian.

2. Ucapan terima kasih kepada LPPM Universitas Kristen Maranatha yang telah mendukung tim peneliti untuk melakukan penelitian, baik secara moril maupun materiil.

\section{REFERENSI}

Atmojo, A., Purnomo, I., \& Muljono, S. (2018). The influence of organizational culture on inpatient staff performance of QIM hospital. Unnes Journal of Public Health, 7(1), 25-29. https://doi.org/10.15294/ujph.v7i1.19213

BPK. (2008). Peraturan pemerintah tentang sistem pengendalian intern pemerintah. Badan Pengawas Keuangan Republik Indonesia. https://peraturan.bpk.go.id/Home/Details/4876

Dhillon, S. R. S., \& Andri, A. (2018). The effect of internal control by using COSO framework on revenue toward employee performance: A case study in public hospital of South of Tangerang, Indonesia. SSRN Electronic Journal. https://doi.org/10.2139/ssrn.3299235

Hardiyansyah. (2018). Kualitas layanan publik: Konsep, dimensi, indikator, dan implementasinya. Gava Media

Hartono, J. (2008). Pedoman survei kuesioner: Mengembangkan kuesioner, mengatasi bias, dan meningkatkan respon (1 ed.). BPFE

Hayat. (2017). Manajemen pelayanan publik. PT Rajagrafindo Persada

Hilda, N. (2014). Strategi inovasi layanan dalam meningkatkan kualitas pelayanan di Kantor Pertanahan Kota Surabaya II. Jurnal Kebijakan dan Manajemen Publik, 2(1). http://journal.unair.ac.id/download-fullpapers-kmpdd76ece88cfull.pdf

IAI. (2017). Peningkatan kapabilitas pengelolaan BLU dan BLUD. Ikantan Akuntan Indonesia Kompartemen Akuntan Sektor Publik

Ilias, N., Abdulatiff, N. K., Zakaria, W. Z. W., \& Wahab, N. (2016). The effects of management control systems on service quality performance in Malaysian local authorities: Management perspective. International Review of Management and Marketing, 6(4), 915-920. http://www.econjournals.com/index.php/irmm/article/view/3053/pdf

Ombudsman Republik Indonesia. (2019). Hasil penilaian survei kepatuhan standar pelayanan publik. Ombudsman Republik Indonesia. https://ombudsman.go.id/perwakilan/news/r/pwk--hasilpenilaian-survei-kepatuhan-standar-pelayanan-publik

Schein, E. H. (2010). Organizational culture and leadership (4 ed.). Jossey-Bass

Setijaningrum, E. (2009). Inovasi pelayanan publik. PT Media Aksara Globalindo

Sugiyono, \& Susanto, D. A. (2015). Cara mudah belajar SPSS dan Lisrel (1 ed.). Alfabeta

Suherlan, D. (2018). RSUD dr. Slamet raih predikat bintang lima, pasien nyinyir. Jabar News. https://jabarnews.com/read/45686/rsud-dr-slamet-raih-predikat-bintang-lima-pasien-nyinyir

Suwarno, Y. (2008). Inovasi di sektor publik. STIA LAN Press

Ulya, F. N. (2019). 6 kendala ini membuat pelayanan kesehatan di Indonesia tidak maksimal. Kompas. $\quad$ https://money.kompas.com/read/2019/08/19/171503026/6-kendala-ini-membuatpelayanan-kesehatan-di-indonesia-tak-maksimal?page=all

Wibowo. (2016). Budaya organisasi: Sebuah kebutuhan untuk meningkatkan kinerja jangka panjang. PT Raja Grafindo Persada

Zaenal, A. (2018). Dinkes Garut buka pusat layanan kedaruratan masyarakat. Antara. https://jabar.antaranews.com/berita/75119/dinkes-garut-buka-pusat-layanan-kedaruratanmasyarakat 